\title{
Jornalismo
}

\section{Telegrafia e modernização da imprensa nas crônicas de Machado de Assis}

\section{Telegraphy and the modernization of the press in Machado de Assis's chronicles}

\section{JUSSARA QUADROS}

Doutora em Teoria Literária pela Universidade Estadual de Campinas (Unicamp) - Campinas, SP, Brasil. <jussaramq@gmail.com>

\section{RESUMO}

O artigo analisa as críticas de Machado de Assis (1839-1908) à telegrafia e sua resistência à informação telegráfica como novo paradigma do discurso jornalístico. Em 1875, um ano apenas após a inauguração do cabo submarino transatlântico, a agência Havas-Reuter abria seus escritórios no Brasil, marcando o início da incorporação do país a uma rede global de comunicações telegráficas. As crônicas do escritor, publicadas entre 18701890, mostram que a modernização tecnológica da imprensa gerou tensões e controvérsias, ameaçando desestabilizar os fortes vínculos entre a literatura e o jornalismo. As invectivas irônicas de Machado de Assis contra a agência Havas revelam seu engajamento nas políticas da imprensa local, por oposição à acelerada internacionalização do mercado de notícias na segunda metade do século XIX.

Palavras-chave: Machado de Assis; Crônicas; Telegrafia; Século XIX; Literatura e Tecnologia.

\begin{abstract}
The article analyses Machado de Assis's (1839-1908) critical view on telegraphy and his resistance to the emergence of telegraphic information as a new paradigm for journalistic discourse. In 1875, only a year after the inauguration of the transatlantic submarine cable, the Havas-Reuter news agency opened its offices in Brazil, both events signaling the moment of Brazil's incorporation in the global networks of telegraphic communication. Machado de Assis's chronicles, published in the 1870s-1890s, show that the technological modernization of the press was controversial, threatening to destabilize the close ties between literature and journalism. Machado's ironic invectives against the Havas agency reveal his commitment to the politics of the local press, in opposition to the accelerated internationalization of the news market in the second half of the $19^{\text {th }}$ century.
\end{abstract}

Keywords: Machado de Assis; Chronicles; Telegraphy; 19 ${ }^{\text {th }}$ century; Literature and Technology 
- screvendo ao longo de toda segunda metade do século XIX em jornais e revistas Uliterárias, Machado de Assis (1839-1908) pôde acompanhar de perto a emergência de novas tecnologias da imprensa. Em sua juventude, as novidades eram as prensas a vapor, o aperfeiçoamento da reprodução litográfica e o advento ainda recente da fotografia. Em carta de novembro de 1866 a seu amigo Quintino Bocaiúva (1836-1912), jornalista brasileiro então residindo em Nova York, Machado demonstrava sua curiosidade e entusiasmo por uma metrópole imaginada à distância como se pertencendo a outra esfera de tempo, o "tempo das linhas telegráficas", e dos ritmos modernos de sua vida urbana:

Estou ansioso por ver cartas tuas e saber que impressões tiveste ao entrar neste grande mundo, o que te parece isso, o que é na realidade. Se tiveres vagar de contar-me tudo isso, acredita que me dás infinito prazer. Gozarei ao menos através das tuas cartas, o que me servirá de satisfação no meio do profundo aborrecimento em que vivo. Ah! tempo das linhas telegráficas, dos meetings, tempo da praça, o teu tempo, enfim! Estou às mãos de Lord Spleen. Adeus, escreve-me, não te esqueças de mim."

(Assis, 2008, pp. 19-20)

A carta, dirigida ao amigo distante, colocava em contraste duas temporalidades: o tempo subjetivo do spleen, o tédio de matriz romântica em que o escritor dizia se encontrar, e a expectativa de uma aceleração do tempo e de um encurtamento das distâncias que surgiam como promessas da recente expansão telegráfica. Aos códigos de intimidade da carta privada vinha unir-se um anseio por conexões públicas mais amplas, como as novas tecnologias da comunicação descortinavam. E ainda 
que o escritor se dissesse nas "mãos de Lord Spleen", ressaltando com isso uma posição, sobretudo, literária, sua carta também enfatizava os vínculos entre avanços tecnológicos e democratização do espaço público. Machado escrevia em 1866, a escravidão nos Estados Unidos havia sido abolida há apenas um ano, o "tempo dos meetings" em sua carta ainda guardava ecos da repercussão dos meetings da campanha abolicionista norte-americana.

Naquele mesmo ano em que o cabo telegráfico submarino entre Estados Unidos e Europa era inaugurado, Quintino Bocaiúva, então encarregado oficial do império para assuntos de imigração em Nova York, também buscava atrair capitais americanos para o estabelecimento de uma linha telegráfica entre os Estados Unidos e o Brasil. Como Machado de Assis frisava em sua carta, o "tempo das linhas telegráficas" era o tempo de Quintino e não o seu, mas como jovem jornalista do liberal Diário do Rio de Janeiro, Machado não deixava de reconhecer o redimensionamento de horizontes que a telegrafia introduzia e seu potencial transformador. Experiência subjetiva, modernização técnica e ideais políticos progressistas apareciam na carta como fenômenos inter-relacionados, e o que entre eles poderia se revelar contraditório, ou inconciliável, ainda não se mostrara relevante.

Mas o que dizer, no entanto, desta afirmação, feita anos mais tarde pelo escritor, em crônica de 1876, na revista Illustração Brasileira: "o que eu apuro de tudo o que nos vem pelo cabo submarino e vapores transatlânticos é que o Oriente acabou e com ele a poesia" (Assis, 2009, p. 61). O comentário irônico do cronista referia-se às notícias da suposta adoção de um regime parlamentar pelo Império Otomano. Mas iria ainda mais longe: anunciava o declínio de um imaginário oriental que o Romantismo transformara em mito, no momento em que o Oriente se incorporava ao espaço-tempo da modernidade. O cronista jogava com estereótipos orientalistas, haréns, dançarinas, eunucos, para satirizar não as tradições islâmicas, mas a ocidentalização que as ameaçava. 
Em outra de suas crônicas da série Quinze Dias, publicada na mesma revista, o escritor transcrevia dos jornais diários a proposta de reformas na Turquia, e a curta vigência da nova constituição, após uma sequência de golpes de estado, suscitava o comentário jocoso do cronista:

A Turquia está a macaquear a Bolívia de um modo escandaloso: muda de sultões como a Bolívia de presidentes e o leitor de camisas. Um sultão ali equivale a um colarinho de papel: dura um passeio. Durou este, ainda assim, mais do que o projeto de constituição, de que já não há notícia, por fortuna do Alcorão."

(Assis, 2009, p. 89)

O interesse de Machado de Assis pela política mundial era possivelmente genuíno, mas a perspectiva irônica e o humor oblíquo de suas crônicas provocavam desconcertantes inversões de pontos de vista. A preocupação com o "89 em ponto pequeno" da Turquia e com as rebeliões no Oriente assumia um tom de farsa quando o cronista os comparava a uma ópera de Wagner mal traduzida, e transformada numa comédia de erros. Nesta comparação, o disparate também provinha da percepção em simultaneidade de acontecimentos heterogêneos e espacialmente afastados, um efeito que a telegrafia e suas redes provocavam, ao acelerar o entrecruzamento de notícias e informações entre centros e periferias.

Notícias mundiais, cabos submarinos e o fim da poesia viam-se justapostos e confrontados na crônica de Machado de Assis como aspectos de uma modernidade emergente frente à qual o escritor parecia reagir com distanciamento irônico. A percepção 
de que transformações se sucediam com maior rapidez, e que poderiam desestabilizar modelos culturais e políticos, ou gêneros literários tradicionais como a poesia, acentuava-se nos anos 1870, quando regiões periféricas como o Oriente, e países periféricos como o Brasil, passavam a ser integrados a um sistema mundial de comunicações, produto da industrialização e do expansionismo econômico das potências europeias.

\section{A emergência de redes telegráficas mundiais}

Quando o cabo transatlântico entre o Brasil e a Europa foi inaugurado em 1874, o Império Britânico, financistas e cartéis de companhias internacionais estavam finalmente próximos de alcançar seu intento de recobrir o mundo com linhas telegráficas. A transformação dos sistemas telegráficos nacionais numa rede integrada mundial havia se tornado possível quando, após vários insucessos, o cabo submarino anglo-americano entre os Estados Unidos e a Europa finalmente fora lançado em 1866. Mas já em 1865, duas linhas de cabos telegráficos submarinos conectavam a Europa e a Índia: uma rota principal atravessando a Pérsia e o Império Otomano, e uma linha em direção ao norte, que atingia a Índia através da Rússia. Em 1870, uma nova companhia dirigida por Charles Siemens (1823-1883) e por Julius Reuter (1821-1889), construíra um sistema de cabos que, partindo de Londres via Berlim, estendia-se a Varsóvia e Odessa, indo até o Mar Negro e de lá a Teerã, onde se interligava aos cabos telegráficos do Golfo Pérsico. Outra importante rede telegráfica, construída e administrada pela The Greater Northern Company, estreitava as comunicações entre a Europa e o Extremo Oriente. Sua vasta extensão de redes telegráficas atravessava a Rússia rumo à Ásia, conectando o continente europeu ao Japão, à China e a Hong Kong (Winseck, 2007, pp. 29-38).

A incorporação do Brasil a este sistema mundial de comunicações foi relativamente tardia. Nas palavras de Irineu Evangelista de Sousa, o Barão de Mauá (1813-1889), em 1871 o Brasil ainda permanecia "segregado do mundo civilizado e alheio ao gozo do 
mais sublime invento que registra o século XIX" (1942, p. 207). Raro representante do novo ímpeto capitalista numa sociedade escravista, Mauá exerceu um papel chave nos novos negócios abertos pela expansão da telegrafia. Sua associação com as duas maiores companhias telegráficas inglesas - The British Telegraph Construction and Maintenance e a The British Indian Rubber, Gutta Percha and Telegraph Company - foi instrumental para que estas obtivessem concessões e subsídios governamentais no Brasil e no Uruguai. Já em 1865, essa união de capitais havia dado origem à The River Plate Telegraph Company of London, responsável pela construção e manutenção de um cabo telegráfico em Montevidéu com conexão para o Brasil (Winseck, 2007, pp. 65-69). O prestígio e a influência de Mauá garantiram ainda às companhias inglesas a concessão para a construção do cabo telegráfico submarino entre o Brasil e a Europa, além de direitos de monopólio de operações de uma extensa rede telegráfica costeira comunicando o Rio de Janeiro e as principais províncias do norte e do sul do país (Berthold, 1922, pp. 7-13).

O imperador D. Pedro II anunciaria o início das obras de construção das novas linhas de cabos em sua Fala do Trono de 1872:

Compraz-mo em anunciar-vos que está contratado, de acordo com o governo português, o assento de um cabo elétrico entre a Europa e o Brasil. No decurso de 1874 já poderemos, em nossas relações com aquele continente, usar de tão maravilhoso instrumento da atividade de nosso século. Trabalha-se com o maior esforço para que fique pronta ao mesmo tempo a linha terrestre, e exclusivamente brasileira, a que vem unir-se ao cabo transatlântico."

(1977, pp. 409-410) 
Ainda que, desde 1852, existissem planos de desenvolver um sistema nacional de telegrafia, as poucas linhas construídas até 1860 restringiam-se ao Rio de Janeiro e às comunicações da Corte com o interior da província. A eclosão da Guerra do Paraguai impulsionou, pela primeira vez, a construção de uma vasta extensão de linhas telegráficas inter-regionais, unindo o Rio de Janeiro aos campos de batalha no sul. Apenas nos anos 1870 a telegrafia se tornaria um serviço regular acessível ao público e, ao final de 1879, treze das vinte províncias do Império já se encontravam ligadas ao Rio de Janeiro por linhas telegráficas terrestres. O sistema telegráfico exclusivamente brasileiro, no entanto, prometido pelo imperador em 1872, não chegaria a concretizarse apesar dos esforços do engenheiro Guilherme S. de Capanema (1824-1908), diretor da Secretaria de Serviços Telegráficos do Império. Capanema defendeu, até o final do século XIX, a importância de um sistema nacional de monopólio estatal (Berthold, 1922, pp. 5-12).

Ao contrário disto, o fluxo estratégico e mais lucrativo de comunicações entre o Brasil e a Europa, e entre as principais cidades litorâneas do país, manteve-se sob controle de companhias inglesas. Em 1873, a concessão de vinte anos para a construção do cabo submarino entre Brasil e Portugal dada ao Barão de Mauá foi transferida para a The Brazilian Submarine Telegraph Company, uma subsidiária da The Eastern Telegraph Company. Do mesmo modo, o monopólio por sessenta anos concedido para a The Telegraph Construction \& Maintenance Company (Telcon) para construção e manutenção da rede submarina costeira também foi transferido para outra subsidiária britânica, a The Western E Brazilian Telegraph Company (Berthold, 1922, pp. 34-36).

Em junho de 1875, menos de um ano após o início das operações da linha telegráfica transatlântica, as agências de notícias internacionais Reuters e Havas abriram escritórios conjuntos em Recife, Salvador, Rio de Janeiro, Montevidéu e Buenos Aires (Read, 2000, 
p. 65). Antes da existência do cabo telegráfico submarino, notícias internacionais, informações financeiras, mensagens governamentais e correspondências privadas dependiam do ritmo lento do tráfico marítimo transatlântico, levando semanas ou mesmo um mês para chegar a seu destino. Através da telegrafia a cabo, mensagens passavam subitamente a ser transmitidas e recebidas em poucas horas. Notícias mundiais passariam a circular mais rapidamente, sendo que a própria noção de notícia sofreria uma completa redefinição ao ser incorporada, através da mediação das agências internacionais, ao circuito mundial das trocas capitalistas (Mattelart, 2000, pp. 8-11).

\section{Agências de notícias internacionais: as suspeitas do cronista}

Através da imagem de um oceano mítico relegado à função de mero repórter da agência Havas, Machado de Assis satirizava a expansão mundial das agências de notícias: “o padre Oceano está perdendo todo o prestígio que lhe haviam dado a poesia e a superstição; hoje é apenas um repórter, bravio às vezes, mas fidelíssimo, - di-lo a agência Havas" (Assis, 2008, p. 124).

$\mathrm{Na}$ metamorfose do oceano em repórter, as novas proezas da técnica, como o cabo submarino, triunfavam sobre uma natureza desencantada. Com o progresso tecnológico o oceano perdia seu prestígio e mistério, e submetia seus antigos poderes às novas forças produtivas. E mais uma vez, Machado de Assis contrapunha a poesia ao utilitarismo dos novos fenômenos de modernização. Na alusão à pretensão de universalidade da Agência Havas, Machado já antevia o que mais tarde irá ser objeto da crítica de um poeta como Mallarmé: a intensificação da instrumentalização da linguagem no século XIX, a expansão irrefreável da universel reportage. A aproximação com o poeta simbolista não é fortuita, ambos os escritores permaneceram infensos aos apologéticos discursos modernizadores 
da segunda metade do século XIX, reagindo a estes com um marcado distanciamento crítico.

Na caricatura de um Oceano-repórter, Machado de Assis emblematizava o declínio dos mitos clássicos, e da literatura, frente ao prestígio ascendente do novo regime de informação representado pela Agência Havas. Mas sua crítica também residia no emprego irônico do superlativo fidelíssimo, que servia para aguçar a desconfiança do leitor, insinuando a possibilidade de seu contrário, de que os despachos telegráficos da Agência Havas pudessem não ser fiéis no registro dos fatos que transmitiam. Nesta mesma crônica de 1878, a paródia de um suposto estilo do cabo voltava a contradizer a crença na exatidão da informação telegráfica:

Hipóteses vagas, mas dúbias, sobre sucessos que improvavelmente se darão ou talvez nunca, conforme os fatos anteriores induzem levemente a suspeitar, sem aliás prejulgar ocorrências presumíveis e não improváveis, conquanto incoercíveis até o presente. Desculpe o cabo se the copio o estilo."

(Assis, 2008, p. 124)

O controle das comunicações transatlânticas por companhias inglesas também gerava suspeitas de que interesses do próprio governo britânico influenciassem o teor das notícias divulgadas pela agência Havas no Brasil, como insinuava Machado em crônica de agosto de 1877: 
A vocação do telégrafo é um logro. Ele pode acertar muitas vezes ou aproximar-se da verdade; mas o logro é a sua vocação. Esta quinzena foi a das 4.000 libras do parlamento inglês. Quando a agência Havas nos disse gravemente que o governo da Inglaterra propusera 4.000 libras para o Ceará, houve pasmo e agradecimento nas fisionomias. O caso era novo; mas os desastres do Ceará são vulgares? Toda gente fiou-se na palavra da agência, cuja gravidade, veracidade e universalidade são conhecidas. Vai senão quando descobre-se que não houve pedido inglês, de libras inglesas ao parlamento inglês. Era o inverso do nosso adágio. O telegrama era só para brasileiro ver. É certo que a agência Havas não se explicou ainda a este respeito; mas devemos acreditar que, se nós pasmamos com a afirmação, ela deve ter pasmado com a retificação, e o efeito nela deve ser maior."

(Assis, 2009, p. 229)

A acusação era grave por tratar-se da devastadora seca do Ceará de 1877, ano em que uma seca de proporções ainda mais avassaladoras dizimava milhões na Índia e em outros protetorados britânicos na Ásia. A crônica aludia à insuficiência de socorro oficial às vítimas de uma fome que tomava a dimensão de uma tragédia mundial, assim como se universalizava o logro praticado pelos impérios, secundado e difundido pela agência Havas. Machado de Assis não foi, absolutamente, o primeiro a lançar invectivas contra a Agência Havas. É possível que a primazia tenha sido de Balzac, que já em 1840, advertira contra o caráter monopolista dos empreendimentos jornalísticos de Charles Havas: “O público talvez acredite que existam muitos jornais (franceses), mas em verdade há apenas um: a Agência Havas” (Balzac, 1868, p. 672). 
Charles Havas (1783-1858) abrira em 1835 um escritório de tradução de notícias estrangeiras, voltado de início a notícias mercantis e anúncios, que se transformara, porém, com a expansão telegráfica, numa rede de agências de notícias com correspondentes e tradutores em toda a Europa. Com as novas redes de cabos submarinos transcontinentais, as três maiores agências europeias de notícias - a francesa Havas, a de Julius Reuter com sede em Londres, e a dirigida por Bernhard Wolff na Alemanha - formariam um cartel em 1870, entrando num acordo de divisão do mundo em zonas nas quais exerceriam direitos exclusivos de operação. A Reuter's Telegraph Company reservou para si o Império Britânico, a Turquia, a Índia, o Extremo Oriente, assim como manteria escritórios conjuntos com a Havas na América do Sul. A Agência Havas exerceria um monopólio de distribuição de notícias na França, Suíça, Itália, Península Ibérica, América Central e, associada à Reuters, no Egito e na América do Sul. Para a The Continental Telegraphen Compagnie de Wolff reservavam-se os direitos de exploração de uma rede de agências e correspondentes abrangendo a Alemanha, Áustria, Escandinávia, Rússia, os Bálcãs e os países nórdicos (Nelbach, 2003, pp. 68-94).

A concentração em tão poucas agências de um poder de controle sobre os fluxos de informação mundial despertava preocupações. Como um jornalista da Vanity Fair advertia, em 1872: “Do modo como são tratadas agora as notícias internacionais, não seria exagerado dizer que aquele que possui o controle dos telegramas tem controle sobre a opinião pública em matéria de negócios estrangeiros ${ }^{1}$." (Nelbach, 2003, p. 77). Não passariam despercebidos os vínculos entre as agências de notícias, as redes mundiais de telegrafia, e as estratégias políticas e econômicas das potências europeias. As crônicas de Machado de Assis insistiriam em questionar a autenticidade da difusão de notícias pelas agências, formulando, da mesma forma, uma oposição entre a brevidade da informação telegráfica e a prosa dos jornais trazidos pelos vapores transatlânticos: 
Seja como for, estou agora de pé atrás com as notícias telegráficas da Europa. [...] Portanto, não me fio mais em telegramas. Quero ver as notícias em boa e esparramada prosa, como no tempo em que os paquetes nos traziam os acontecimentos, novos em folha e nas folhas. Pode a agência contar-me o que lhe parecer. Quisera acreditar nas vitórias dos turcos; mas como, depois das libras inglesas? Melhor é apelar do telégrafo para o vapor; com isto não ofendo o progresso: ambos são seus filhos."

(Assis, 2009, p. 230)

A contraposição entre o telégrafo e o vapor era aquela entre o sistema telegráfico transcontinental e o sistema postal vinculado à navegação transatlântica. Ambos eram responsáveis pelo dinamismo das relações com o mundo no século XIX, mas a transmissão telegráfica já operava em intervalos de minutos, potencialmente prometendo tornar as comunicações à longa distância independentes de meios de transporte. A recepção de notícias tornara-se tecnologicamente mediada, o cronista, porém, ao recomendar o "pé atrás", advertia o leitor contra uma crença irrefletida nas vantagens do telégrafo: "Há homens simplórios que desde a inauguração do cabo estão plenamente convencidos da inutilidade dos paquetes, enquanto a notícias. [...] Nunca os paquetes foram mais necessários do que hoje" (Assis, 2009, p. 218). Linhas regulares de vapores transcontinentais, os "paquetes", supriam a imprensa local de jornais estrangeiros dos quais notícias e matérias internacionais costumavam ser transcritas.

Estas práticas de apropriação persistiam sendo comercialmente mais vantajosas do que os serviços telegráficos da agência Havas. Para a imprensa local, subscrever jornais estrangeiros significava apropriar-se de uma pluralidade de fontes noticiosas, e de relatos de acontecimentos que ainda guardariam traços de sua origem numa 
esfera pública. Agências como a Havas, por sua vez, por seu caráter transnacional e pelo alto grau de especialização técnica de suas práticas, transformavam a notícia em informação descontextualizada, cujo forte apelo de atualidade via-se, na mesma medida, fortemente constrangido pela brevidade telegráfica.

Ao enfatizar a importância da prosa, a crônica de Machado deixava transparecer o receio de que o novo estatuto da notícia que então despontava viesse a desestabilizar os fortes vínculos entre a literatura e os discursos da imprensa, ou mesmo ameaçar o valor substancial da opinião. E sugeria que uma opinião esclarecida dependia da leitura da prosa esparramada dos jornais e de uma leitura desconfiada da notícia telegráfica.

Nessas crônicas de 1877, já se observava a pronunciada indução irônica a suspeita, aliada a uma tática de interpelação provocativa do leitor que, a partir de Memórias Póstumas de Brás Cubas (1880), iriam se tornar dispositivos estruturais dos romances da chamada segunda fase da obra literária de Machado de Assis. No entanto, uma função diversa da que viria a cumprir de modo mais ostensivo em Memórias Póstumas de Brás Cubas, romance no qual, como observou Roberto Schwarz, "os jogos com o leitor não se destinam a construir, mas a destruir a hipótese de um entendimento esclarecido com o público" (1990, p. 172). Não seria o caso de tratar aqui das inúmeras diferenças entre a crônica e o romance machadianos, mas de apontar para a diferença saliente entre a enunciação autobiográfica, entre a voz privada do personagem-narrador Brás Cubas, com seus códigos hierárquicos de classe, e a performance de vozes que se articulam nas crônicas, inseparáveis da enunciação coletiva do jornal, e das trocas sociais e simbólicas da esfera pública que encontravam nos discursos da imprensa sua tradução.

Ainda que a ironia lhes emprestasse certa superioridade, as vozes das crônicas não se afastam nunca do solo de uma cotidianidade pública e contingente, e mesmo o tom conversacional, familiar e íntimo, adotado muitas vezes pelo cronista, via-se enquadrado pelos horizontes do jornal e da cidade. A crônica preservaria, assim, ainda 
que o submetendo às ambiguidades da ironia, e por seus vínculos mais estreitos com o espaço público, o pacto comunicacional que em Memórias Póstumas seria minado pela derrisão.

Nem os protocolos de leitura, nem os leitores implícitos das crônicas e do romance seriam os mesmos, mas ambos os gêneros internalizariam uma crítica ao leitor concebida e transformada por Machado de Assis em procedimento estilístico, no mesmo momento em que a telegrafia ameaçava mudar drasticamente os modos de recepção de notícias e as expectativas dos leitores. No novo regime da informação telegráfica, o primado da atualidade criava uma expectativa pelas últimas notícias, que poderiam chegar a qualquer momento do dia. Machado faria uma paródia de dias vividos sob a expectativa de notícias de uma revolução no sul. O cronista registrava com exatidão de minutos, não só os ritmos da informação telegráfica, mas a irrupção de rumores e boatos, desencadeados pela ambiguidade de um primeiro telegrama mal interpretado:

O dia 10 trazia uma notícia no bolso, nada menos que achar-se embarcado o presidente do Rio Grande. Embarcado por quê? Esta pergunta foi repetida, ouvida, comentada durante todas as vinte e quatros horas do sobredito dia 10 [...].Os telegramas saíam aos pares, os pares saíam aos telegramas (se me é lícita a antítese), e nada se sabia. [...] Às dez horas e meia do dia 11 [...] soube-se que no Rio Grande rebentara uma revolução, que o General Osório ficava na presidência da república; que um general, à frente das forças legais, batia-se com as forças da revolução [...]."

(Assis, 2009, pp. 115-116) 
A crônica retratava com muito humor as reverberações e transfigurações sofridas pelas notícias ao repercutirem no espaço público:

Era uma hora e doze minutos quando começou a espalhar-se a notícia de que uma constituinte fora eleita [...]. Mal começaram estas notícias a percorrer o espaço que vai da casa Garnier ao ponto dos bonés, caiu uma nova bomba, - a bomba das alianças."

(Assis, 2009, pp. 116-117).

Rumores sobre os acontecimentos distantes intensificavam-se, revoluções faziam-se e desfaziam-se nos intervalos entre telegramas:

Às cinco e três quartos deixara de existir a constituinte, dissolvida pelo presidente; às seis e vinte minutos caía o presidente, ante um voto da nova constituinte. Esta sucumbe depois de um quarto de hora de trabalho, deixando um presidente que igualmente sucumbe depois de cinco minutos de vadiação [...]."

(Assis, 2009, pp. 116-117)

Ao final, é a credibilidade prosaica do jornal matinal deixado à porta de seus assinantes que reconduz os fatos a sua justa proporção: “À madrugada do dia 12, [...] os entregadores dos jornais metiam estes por baixo das portas. Os mais curiosos 
levantam-se, lêem e ficam sabendo que não houve revolução nem coisa que se parecesse com isso" (Assis, 2009, p. 117).

A crônica zombava das pretensões à objetividade da telegrafia ao associá-la ao boato e ao rumor das ruas, mas também insinuava os riscos de sua instrumentalização política. A preocupação com o potencial de disseminação da mensagem telegráfica, pelo amplo alcance de sua transmissão rápida através de redes regionais e internacionais, seria uma constante ao longo do século. Escrevendo em 1893, Joaquim Nabuco (1849-1910) descreveria o telégrafo como "a principal das máquinas políticas", imaginando a hipótese de uma situação bastante semelhante à descrita na crônica de Machado: "um operador, senhor dos fios desta cidade, que se quisesse divertir, podia de manhã depor e à noite restabelecer os governos de todos os estados da União" (Nabuco, 2003, p. 43).

Na crônica de Machado e na observação de Nabuco, o mesmo receio aflorava de que a telegrafia pudesse romper a ordem centralizadora do poder político. Ambos julgavam a tecnologia telegráfica como exógena à representação política e suas mediações, a concisão telegráfica mostrando-se em tudo oposta aos protocolos discursivos da eloquência política e da prosa jornalística.

As objeções de ambos à telegrafia apontavam ainda para a autenticidade incerta da mensagem telegráfica, para um meio tecnológico que parecia propiciar a propagação de mensagens falsas, como se por trás da inscrição codificada dos telegramas também o emissor mais facilmente pudesse ocultar a si mesmo e suas intenções. O risco mais importante, no entanto, para o qual as crônicas de Machado de Assis advertiriam, era o de se creditar um valor automático de verdade à mensagem e à notícia telegráfica, quando estas, como julgava o escritor, não passariam de formas empobrecedoras de escritura e de linguagem, um tatibitate. Como na crônica abaixo, na qual, a partir de um erro de tradução, e através do diálogo entre o cronista e o funcionário da companhia 
telegráfica inglesa, o que seria o ramo local do mercado internacional de notícias aparecia como um mero balcão de telegramas:

Em Venezuela (diz um telegrama de Nova York, de 25, publicado no dia 26) dissolveu-se o partido do General Guzmán Blanco. Fiquei como não imaginam; tanto que não tive tempo de vir cumprimentá-los, segundo o meu desejo. Corri ao escritório da companhia telegráfica, para saber se não haveria erro na tradução do telegrama. Podia ser patrulha, podia ser patuscada; podia ser mesmo um batalhão. Nós dissolvemos batalhões. Partido é que eu achava."

(Assis, 1990, pp. 197-198)

A representação jocosa do português falado pelo funcionário inglês da companhia serviria à crônica para ressaltar a analogia entre suas frases curtas, cheias de erros, e a linguagem dos telegramas. A crítica de Machado de Assis em parte denunciava, em parte utilizava como recurso cômico, a desproporção entre a brevidade da enunciação telegráfica e os possíveis efeitos que uma simples troca de verbos ou deslizes semânticos poderiam provocar na realidade:

- Está aqui telegrama, senhorr, disse-me o inglês de alto a baixo, com um ar de sobressalente; senhorr pode egzamina ele, e reconhece que Company não tem interesse em inventa telegramas.

- Há de perdoar, mas o Príncipe de Bismarck pensa o contrário. 
- Contrário à Company?

- Não, aos telegramas. Disse ele, uma vez, em aparte a um orador da Câmara. 'O sr. Deputado mente como um telegrama.' Mas eu não vou tão longe; os telegramas não mentem, mas podem ser tatibitate...

- Senhorr fala latim; eu deixa senhorr...

E foi para dentro o inglês; desci as escadas e vim para a rua, desorientado e cada vez mais curioso de achar explicação à notícia, que me parecia estrambótica. Custava-me entender que um partido se dissolvesse assim, em certo dia, como se expede um decreto. Compreendo que uma reunião familiar se dissolve, em certa hora; [...] Mas um partido, uma vegetação política, lá me custava engolir."

(Assis, 1990, pp. 197-198)

Sem mencionar seu nome, a crônica aludia à The Western and Brazilian Telegraph Company e, indiretamente, ao controle britânico sobre o fluxo de comunicações telegráficas na América do Sul, sugerindo suas implicações políticas. O fato de Machado de Assis ter sido, além de escritor, um alto funcionário do Ministério da Agricultura, Comércio e Obras Públicas, deve ter contribuído para sua crítica às companhias telegráficas. Ainda que exercesse suas funções na Diretoria de Agricultura, é pouco provável que fosse alheio às atividades dos demais setores do ministério, os quais foram responsáveis, na segunda metade do século, pelas decisões sobre as obras de modernização da infraestrutura do país: estradas de ferro, portos, telegrafia, serviços urbanos de transporte e iluminação, majoritariamente construídos e administrados por companhias inglesas. A posição de funcionário de Estado tornava ainda mais significativa a resistência do escritor aos processos de modernização. Desqualificar o progresso pela ironia, pela desconfiança, e mesmo pelo silêncio, é um dos traços paradoxalmente modernos da obra de Machado de Assis. 
Avesso à exaltação da natureza brasileira e do exotismo em sua literatura, o romancista também não demonstrou entusiasmo frente aos avanços tecnológicos de seu tempo, antes os tratando com reticência e descrédito. E se coube à telegrafia ser o objeto de suas críticas mais explícitas, foi por seus efeitos incidirem diretamente sobre a linguagem. "A ciência é uma pessoa demorada e prudente, não precisa de máquinas para falar e escrever depressa" (Assis, 1998, p. 100), observação machadiana que parece tingida de conservadorismo, em sua recusa à aceleração mecânica, mas que aponta para a tensão entre a prosa e a informação telegráfica assinalada nas crônicas. A rapidez do registro telegráfico dos fatos encontrava sua contraposição, em Machado de Assis, no deter-se da reflexão sobre o acontecimento, cuja complexidade o cronista resgatava através da narração e com o auxílio da memória. Machado não concebia o acontecimento e sua experiência segundo os padrões então emergentes da atualidade, ao contrário, em suas crônicas e romances não existiam acontecimentos que não fossem, de algum modo, perpassados e mediados pela memória, memória social e coletiva, memória privada. Como se dizia no século XIX, repórteres têm pernas, cronistas, reminiscências.

\section{REFERÊNCIAS}

ASSIS, Machado de. Correspondência (1860-1869). Rio de Janeiro: Academia Brasileira de Letras, 2008 . v. 1. . História de Quinze Dias. Org. John Gledson e Lúcia Granja. Campinas: Editora da Unicamp, 2008. . Obra Completa. Rio de Janeiro: Aguilar, 1959.

. Bons Dias! São Paulo: Hucitec, 1990.

Balas de Estalo. Org. Heloisa Helena Paiva De Luca. São Paulo: Annablume, 1998.

. Notas Semanais. Org. Leonardo Affonso de Miranda Pereira. São Paulo: Editora da Unicamp, 2009.

BALZAC, Honoré de. Oeuvres Complètes. Paris: Michel Lévy Frères, 1868. v. XXIII.

BERTHOLD, Victor M. History of the Telephone and Telegraph in Brazil, 1851-1921. New York: American Telephone and Telegraph Company, 1922. 
CHALHOUB, Sidney. Machado de Assis Historiador. São Paulo: Companhia das Letras, 2003.

Falas do trono: desde o ano de 1823 até o ano de 1889, acompanhadas dos respectivos votos de graça. Brasília: Instituto Nacional do Livro, 1977.

LEFEBVRE, Antoine. Havas: les arcannes du pouvoir. Paris: Grasset, 1992.

MAGALHÃES JR., Raimundo. Machado de Assis, vida e obra. Rio de Janeiro/São Paulo: Record, 2008.

MATTELART, Armand. Networking the World, 1794-2000. Minneapolis: University of Minnesota Press, 2000. NABUCO, Joaquim. A Revolução Estrangeira durante a Revolta de 1893. Brasília: Edições do Senado Federal, 2003. v. 21.

NELBACH, Alex. The Software of Empire: Telegraphic News Agencies and Imperial Publicity - 1865-1914. In: CODEL, Julie F. Imperial co-histories, national identities and the British, and the colonial news, Associated University Presses, 2003.

READ, Donald. The Power of News: The History of Reuters 1849-1989. Oxford: Oxford University Press, 2000.

REID, James J. Crisis of the Ottoman Empire: prelude to collapse 1839-1878. Stuttgart: Steiner, 2000.

SCHWARZ, Roberto. Um Mestre na Periferia do Capitalismo: Machado de Assis. São Paulo: Duas Cidades, 1990. SOUSA, Irineu Evangelista de Sousa. Autobiografia ('Exposição aos credores e ao público') seguida de 'O Meio Circulante do Brasil'. Rio de Janeiro: Zélio Valverde, 1942.

WINSECK, Dwayne; PIKE, Robert. Communication and Empire, Media, Market, and Globalization 1860-1930. Durham: Duke University Press, 2007.

\section{NOTA}

1 "As foreign news are now managed, it is not too much to say that he who has control of telegrams has control of public opinion in foreign affairs" (Nelbach, 2003, p. 7).

\section{Endereço da autora:}

Jussara Quadros < jussarama@gmail.com>

Av. Borges de Medeiros, 1121/901

CEP 90.020-025, Porto Alegre, RS, Brasil 